\title{
Editorial
}

\section{Psicopatologia e alteridade: dimensões éticas e políticas}

\section{Psychopathology and alterity: ethical and political dimensions}

\author{
Ana Maria Galdini Raimundo Oda*1 \\ Cláudio E. M. Banzato*2 \\ Mário Eduardo Costa Pereira*3 \\ Clarissa de Rosalmeida Dantas*4 \\ Paulo Dalgalarrondo*5
}

O tempo é a minha matéria, o tempo presente, os homens presentes, a vida presente.

Carlos Drummond de Andrade

Tal qual o poeta, cremos que a psicopatologia poderia anunciar que tem como sua matéria a vida presente, os seres humanos do presente, o tempo presente com seu variado cortejo de angústias, medos e esperanças. É disto que tratamos neste editorial, do presente momento no Brasil.

Partimos do suposto que se designamos como psicopatologia(s) o esforço de apreender e articular discursivamente o sofrimento psíquico, em seus infinitos contornos e configurações - o

*1,2,3,4,5 Universidade Estadual de Campinas - Unicamp (Campinas, SP, Brasil). 
que será sempre feito de forma incompleta, pois é de um sujeito que se trata — necessariamente ela nos imporá uma tomada de posição ética diante do padecer humano (Pereira, 1998).

Como aponta Umberto Eco (2000), a "dimensão ética começa quando entram em cena outros" (p. 42), quando reconhecemos o imperativo de respeitar nos outros as mesmas exigências que consideramos irrecusáveis para nós mesmos. Lembra o mesmo autor que tal posição ética diante dos outros é uma aquisição relativamente recente na história da civilização humana. E a civilização, a história nos mostra, é uma conquista provisória e frágil. Podemos constatar que parece não existir aqui algum efeito "catraca", que bloqueie os retrocessos civilizatórios, pois o repertório humano não encontra limites, em um sentido ou em outro, do mais elevado ao mais baixo.

Assim, toda psicopatologia precisa explicitar a visão de homem e de mundo da qual é tributária e nenhuma escapa de se confrontar com os múltiplos determinantes da fragilidade humana: da natureza que não responde aos nossos anseios, da vulnerabilidade do corpo ao desamparo original, das renúncias impostas pelo desenvolvimento da cultura aos precários laços sociais nela constituídos, nada é certo, seguro e garantido. É com essa 694 mistura caótica que nos deparamos quando nos dispomos a escutar e abordar o mal-estar e o sofrimento psíquico de outras pessoas, em seus variados contextos de vida. E é com isso que todos nós temos que lidar: se algo é certo, é a incerteza.

Conforme já assinalado, o ato fundador da psicopatologia é o interesse genuíno pela alteridade, pela subjetividade de outros. E esse interesse é indissociável do respeito e do reconhecimento mútuos implicados em todo verdadeiro encontro humano. As diferenças devem caber no espaço intersubjetivo que se cria a cada encontro, e é isso que permite o cuidado com os outros.

Em suma, concluímos que a razão de ser da psicopatologia não pode ser outra senão almejar contribuir para o cuidado do padecer humano. E, se concordamos com Fernando Pessoa (1955) quando diz que "A alma de outrem é outro universo" (p. 159), tal cuidado sempre se dará no âmbito de uma compreensão reconhecidamente limitada, inexata e temporária daquele que sofre.

Nesse sentido, é evidente que a psicopatologia, como disciplina que se fundamenta na investigação da diferença tida como algo de radical e insuperável, é o avesso da violência e da intolerância - nascidas da certeza de si e degeneradas no desaparecimento do subjetivo em face a supostos ideais 


\section{EDITORIAL}

absolutos - que negam e suprimem a diferença e a alteridade. Eis aqui as dimensões éticas e políticas de uma psicopatologia digna do nome, o que não podemos deixar de repetir enfaticamente.

Por fim, acreditando que a poesia possa ser uma boa guia, e inspirados pelo poeta, sugerimos que sigamos presos à vida, que olhemos solidariamente para os que, como nós, "estão taciturnos mas nutrem grandes esperanças" e, sobretudo, que não nos afastemos, "não nos afastemos muito" neste largo presente (Andrade, 1940/2012, p. 34).

Referências

Andrade, C.D. de (2012). Mãos dadas. In C. D. de Andrade, Sentimento do mundo (p. 34). São Paulo, SP: Companhia das Letras. (Trabalho original publicado em 1940).

Eco, U. (2000). Quando outros entram em cena, nasce a ética. In U. Eco, C.M. Martini, Em que crêem os que não crêem? (p. 42-50). Rio de Janeiro, RJ: Record.

Pereira, M. E. C. (1998, março). Formulando uma Psicopatologia Fundamental. Revista Latinoamericana de Psicopatologia Fundamental, 1(1), 60-76.

Pessoa, F. (1955). Como é por dentro outra pessoa. In F. Pessoa, Poesias Inéditas (1930-1935)(p. 159). Lisboa, Portugal: Ática. Recuperado em 11 nov. 2008, de: $<\mathrm{http}: / /$ arquivopessoa.net/textos/2784>.

Citação/Citation: Oda, A. M. G. R., Banzato, C. E. M., Pereira, M. E.C., Dantas, C. de R., Dalgalarrondo, P. (2018, dezembro). Editorial. Psicopatologia e alteridade: dimensões éticas e políticas. Revista Latinoamericana de Psicopatologia Fundamental, 21(4), 693-696. http:// dx.doi.org/10.1590/1415-4714.2018v21n4p693.1

Editores do artigo/Editors: Ana Maria Galdini R. Oda e Sonia Leite

Recebido/Received: 16.11.2018 / 11.16.2018 Aceito/Accepted: 20.11.2018 / 11.20.2018

Copyright: (C) 2009 Associação Universitária de Pesquisa em Psicopatologia Fundamental/ University Association for Research in Fundamental Psychopathology. Este é um artigo de livre acesso, que permite uso irrestrito, distribuição e reprodução em qualquer meio, desde que o autor e a fonte sejam citados / This is an open-access article, which permits unrestricted use, distribution, and reproduction in any medium, provided the original authors and sources are credited. 


\section{Ana Maria Galdini Raimundo Oda}

Psiquiatra; Doutora em Ciências Médicas; Professora do Departamento de Psicologia Médica e Psiquiatria da Faculdade de Ciências Médicas da UNICAMP (Campinas, SP, Br). Editora da Revista Latinoamericana de Psicopatologia Fundamental.

Rua Tessália Vieira de Camargo, 126 - Cidade Universitária “Zeferino Vaz" 13083-887 Campinas, SP, Br. anaoda@fcm.unicamp.br

\section{Cléudio E. M. Banzato}

Psiquiatra; Doutor em Filosofia; Professor Titular do Departamento de Psicologia Médica e Psiquiatria da Faculdade de Ciências Médicas da UNICAMP (Campinas, SP, Br). Rua Tessália Vieira de Camargo, 126 - Cidade Universitária "Zeferino Vaz"

13083-887 Campinas, SP, Br.

cbanzato@fcm.unicamp.br

\section{Clarissa de Rosalmeida Dantas}

Psiquiatra; Doutora em Ciências Médicas; Professora do Departamento de Psicologia Médica e Psiquiatria da Faculdade de Ciências Médicas da UNICAMP (Campinas, SP, Br). Rua Tessália Vieira de Camargo, 126 - Cidade Universitária "Zeferino Vaz" 13083-887 Campinas, SP, Br. crdantas@fcm.unicamp.br

\section{Mario EduardoCosta Pereira}

Psiquiatra; Psicanalista; Professor titular de Psicopatologia Clínica pelo Laboratoire de Psychopathologie Clinique et Psychanalyse da Aix-Marseille Université (França); Livre-Docente em Psicopatologia do Departamento de Psicologia Médica e Psiquiatria da Faculdade de Ciências Médicas da UNICAMP (Campinas, SP, Br), onde dirige o Laboratório de Psicopatologia: Sujeito e Singularidade (LaPSuS); Diretor do Núcleo de São Paulo do Corpo Freudiano - Escola de Psicanálise.

Rua Tessália Vieira de Camargo, 126 - Cidade Universitária "Zeferino Vaz" 13083-887 Campinas, SP, Br.

marioecpereira@uol.com.br

\section{Paulo Dalgalarrondo}

Psiquiatra; Professor Titular do Departamento de Psicologia Médica e Psiquiatria da Faculdade de Ciências Médicas da UNICAMP (Campinas, SP, Br).

Rua Tessália Vieira de Camargo, 126 - Cidade Universitária “Zeferino Vaz" 13083-887 Campinas, SP, Br.

pdalga@fcm.unicamp.br

\section{(cc) BY-NC}

This is an open-access article, which permits unrestricted use, distribution, and reproduction in any medium for non-commercial purposes provided the original authors and sources are credited. 